\title{
PROTOTIPAGEM RÁPIDA: UM COMPARATIVO ENTRE UMA TECNOLOGIA ADITIVA E UMA SUBTRATIVA
}

Paula Lumi Goulart Nishimura

Universidade Estadual Paulista "Júlio de Mesquita Filho" (UNESP)

lumi.paula@gmail.com

Osmar Vicente Rodrigues, $\mathrm{Dr}$

Universidade Estadual Paulista "Júlio de Mesquita Filho" (UNESP)

osmar@faac.unesp.br

Galdenoro Botura Júnior, Dr

Universidade Estadual Paulista "Júlio de Mesquita Filho" (UNESP)

galdenoro@gmail.com

Letícia Alcará da Silva

Universidade Estadual Paulista "Júlio de Mesquita Filho" (UNESP)

lalcar4@gmail.com

Resumo: A Prototipagem Rápida (PR) pode ser aplicada tanto na confecção de protótipos quanto na produção de produtos para o uso final (Manufatura Rápida), pois é capaz de criar peças com geometrias complexas, com alta precisão dimensional, e executar partes internas sem necessitar de montagens. Embora as tecnologias aditivas, onde as camadas são sobrepostas uma a uma com deposição de material, sejam as mais populares na Prototipagem Rápida, existem também as tecnologias subtrativas, na qual a máquina remove material a partir de um bloco até obter a peça desejada. A PR pode otimizar o processo de produção de um produto, por isso é importante que o tipo de tecnologia seja escolhido adequadamente. Este trabalho apresenta a produção de duas peças a partir de um mesmo modelo, uma confeccionada com a tecnologia aditiva e outra com a subtrativa, e mostra resultados da comparação de ambos os processos.

Palavras-chave: Prototipagem Rápida; Tecnologia Aditiva; Tecnologia Subtrativa; Digitalização 3D; Impressão 3D; Manufatura Rápida.

Abstract: Rapid Prototyping (RP) can be applied in the production of prototypes as well as in the production of end-use products, because is able to create objects with complex geometries and high dimensional accuracy, and even fabricate internal parts without requiring any type of fitting. Although the additive technologies, in which materials are overlaped layer by layer, are the most popular in Rapid Prototyping, there are also subtractive technologies in which materials are removed from a block 
obtaining the desired part. The RP can improve a product's process of production, so it is important that the type of technology is properly chosen. This study aims to compare both production techniques by performing a case study and analyzing the advantages and disadvantages for each one of them.

Keywords: Rapid Prototyping; Additive Technology; Subtractive Technology; 3D digitalization; 3D Printing; Rapid Manufacturing.

\section{INTRODUÇÃO}

A fim de otimizar a produção de seus produtos, através da melhoria de seu processo de desenvolvimento do produto (PDP), aumento da qualidade e da competividade, muitas empresas investem cada vez mais em novas tecnologias, como a Prototipagem Rápida (PR).

Tecnologias de PR são utilizadas na fabricação de modelos, protótipos e produtos, seja através da sobreposição sucessiva de camadas (Impressão 3D), como também por meio da remoção de materiais, como a usinagem, por exemplo, utilizando para isso, máquinas e equipamentos automatizados, operados por CNC - Comando Numérico por Computador.

Embora a PR tenha se popularizado apenas há poucos anos, podem ser encontrados registros dela desde a década de 70 (VOLPATO, 2007). Esta popularização ocorreu devido, principalmente, ao barateamento da tecnologia (tanto dos equipamentos, quanto dos insumos), porque as primeiras patentes passaram a ser de domínio público, o que favoreceu a criação de máquinas e tecnologias genéricas com preços mais acessíveis. Essa redução de preço possibilitou mais investimentos de empresas, inclusive as pequenas e médias, na área.

De acordo com Volpato (2007), além de acelerar o PDP, possibilitar testes, para evitar possíveis falhas, e facilitar uma melhor comunicação entre os membros do projeto, a PR é capaz de trabalhar detalhes precisos na peça e executar geometrias complexas com mais liberdade do que um processo convencional, inclusive podendo gerar peças prontas para o uso, num processo conhecido como Manufatura Rápida (MR). Dentre as vantagens, soma-se também a redução de material usado na confecção da peça, a automatização do processo, e o fato de que a PR dispensa o uso de moldes e algumas ferramentas ao longo do PDP.

Tecnologias de PR possibilitam a produção de modelos físicos em três dimensões, cujas estruturas são obtidas através de informações de um modelo geométrico virtual, criado em softwares de modelamento 3D geradores de arquivos CAD - Desenho Assistido por Computador.

Devido principalmente ao alto valor de alguns insumos, o custo do processo de Prototipagem Rápida ainda é alto, por isso traz maiores vantagens à medida que o número de peças produzidas aumenta, pois o custo hora/máquina acaba sendo reduzido pelo número de peças produzidas. Vale ressaltar que a criação de protótipos possibilita a realização de testes e provas, a fim de minimizar os erros no final do processo, e assim melhorar o PDP.

Como o processo de produção de uma peça varia de tecnologia para tecnologia, é importante identificar e escolher a opção mais viável para a execução do 
projeto, a fim de otimizar seu processo de produção e evitar possíveis imprevistos. Tendo em vista esta observação, o objetivo do presente artigo é apontar as vantagens e desvantagens da aplicação de dois diferentes tipos de tecnologia de PR (uma aditiva e uma subtrativa) através de um estudo de caso, que é a execução do corpo de uma furadeira, cujo arquivo é "open source" (uso livre).

Os modelos a serem comparados foram obtidos através do equipamento Envisiontec Ultra (tecnologia aditiva baseada na resina pelo processo de SLA Stereolithography), e da Fresadora CNC Roland MDX 540 (tecnologia subtrativa), disponíveis no CADEP (Centro Avançado de Desenvolvimento de Produtos) - da Unesp de Bauru, onde este trabalho foi desenvolvido. Serão levadas em conta as seguintes variáveis para a comparação: preço, tempo de produção, material, qualidade de acabamento e fidelidade ao modelo CAD.

\section{TECNOLOGIAS ADITIVAS E SUBTRATIVAS DE PROTOTIPAGEM RÁPIDA}

\subsection{Tecnologias Aditivas}

Como foi dito anteriormente, fazem parte da PR, as tecnologias aditivas e subtrativas. Nas aditivas, a máquina decodifica o arquivo em 3D, fatia esse arquivo em camadas, e produz a peça através da sobreposição sucessiva das camadas de material. A principal vantagem do uso das tecnologias aditivas é a facilidade com que a máquina constrói os mais elaborados e diversos tipos de geometrias, inclusive com detalhes em espaços internos e negativos, dispensando o uso de moldes e outras ferramentas de fabricação.

As tecnologias aditivas podem ser divididas em três tipos: aquelas baseadas nos líquidos - como as resinas -, nos sólidos - materiais em forma de filamentos ou lâminas -, ou no pó; todas utilizando diferentes processos de produção e materiais (VOLPATO, 2007). No CADEP existem três tipos de máquinas aditivas. São elas: a Z-Printer 650 , na qual o material (gesso) é solidificado através de um material aglutinante, formando assim, as camadas que compõem o objeto; a Envisiontec Ultra, que produz protótipos através de uma resina foto polimérica, que se solidifica com o contato de luz UV; e a Cube $x$ Duo que produz peças através de sobreposição do filamento de plástico, pelo processo FDM - Fused Deposition Modeling.

Para este artigo, a tecnologia escolhida foi a Envisiontec Ultra. Essa tecnologia é capaz de produzir peças de um plástico com $85 \%$ das características do ABS, que é um plástico de engenharia, com ótimo acabamento superficial e em pouco tempo, se comparado às outras tecnologias.

\subsection{Tecnologias Subtrativas}

Neste tipo de tecnologia, o modelo final é obtido através de remoção de material a partir de um bloco. A produção de peças através das tecnologias subtrativas costuma ser mais barata do que nas aditivas, cujo custo dos insumos, assim como da hora/máquina, costumam ser maiores. Outra vantagem é permitirem o uso de uma vasta gama de materiais, como madeira, MDF, plástico e alumínio.

No CADEP existem duas máquinas de tecnologia subtrativa: a fresadora CNC Roland MDX 540 com 4ㅇe eixo rotacional ZCL 540", responsável por usinar peças menores e mais complexas, e a Router CNC 3D Transform 2000/2 com área de usinagem de $2.550 \mathrm{~mm} \times 1.850 \mathrm{~mm}$, que executa trabalhos com dimensões maiores, para trabalhos tanto em 2D quanto em 3D. 
A MDX 540 foi escolhida para o trabalho devido à sua alta qualidade de acabamento superficial e sua precisão dimensional.

\section{MATERIAIS E MÉTODOS}

\subsection{Materiais}

Quadro 1 - Materiais.

Computador desktop com Processador Intel Core2Duo, memória RAM de 4GB e Sistema

Operacional de 64 Bits, Windows 7 Home Premium

Máquina de Prototipagem Rápida Envisiontec Ultra

Fresadora CNC Roland MDX 540 com 40 eixo rotacional ZCL 540

Sistema ótico de digitalização 3D móvel GOM Atos | 2M

Software SolidWorks 2011

Software Magics Envisiontec Ultra 1.0

Software Ultra Control II

Software Perfactory Start Center 2.7

Software Magics 17.02

Software SRP Player 1.23

Software ATOS Professional V7.5 SR1

Bloco de Acrílico (PMMA - Polimetilmetacrilato) medindo 326mm x 173mm x 36mm

Resina SI500

Álcool isopropílico

Lixas d'água com gramaturas de 120 a 600

Fresa esférica de aço marca Hanita 402103000RT

Fresa cônica de aço marca Onsrud 37-20

Fonte: Elaborado pelo autor, com base na pesquisa realizada.

\subsection{Métodos}

Inicialmente foi escolhido um modelo, no caso metade do corpo de uma furadeira (peça) disponível no site "GrabCad", a ser executado pelas duas tecnologias. Esta peça teve algumas alterações feitas pelos bolsistas do CADEP a fim de prepará-la para o processo. O arquivo original foi alterado no software SolidWorks 2011, no qual foi gerada uma "casca" deste corpo de furadeira.

Em seguida, o arquivo foi convertido em STL (extensão reconhecida pelas tecnologias de PR), e usado como base na produção de duas peças iguais, mas através de tecnologias e processos diferentes.

Para a produção da peça na MDX 540, já em formato STL, o arquivo foi inicialmente avaliado no software Magics 17.02 (Figura 1) para a busca de possíveis erros (o que não foi encontrado). E por meio do software SRP Player 1.23 (Figura 2), foram gerados os parâmetros da usinagem do modelo em questão.

Em função do segredo industrial, a única informação fornecida pelo fornecedor da resina SI500, utilizada pela Envisiontec Ultra, é que esta possui $85 \%$ das características do ABS - Acrilonitrila Butadieno Estireno. Sem saber a real composição da resina, poderia ser utilizado para usinagem na MDX 540 qualquer outro material, desde que permitisse o uso dos mesmos parâmetros de usinagem do $A B S$, que é a única referência de material informada pelo fabricante. Como o Acrílico (PMMA - 
Polimetilmetacrilato), pode ser usinado com os mesmos parâmetros de usinagem do $A B S$, ele foi o escolhido para a confecção da peça na MDX 540.

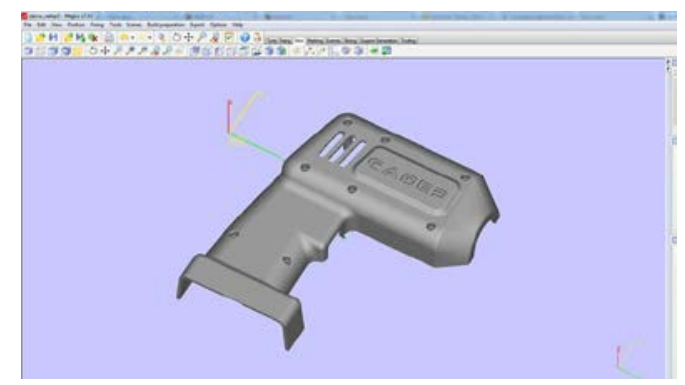

Figura 1 - Magics 17.02. Fonte: Elaborado pelo autor, com base na pesquisa realizada.

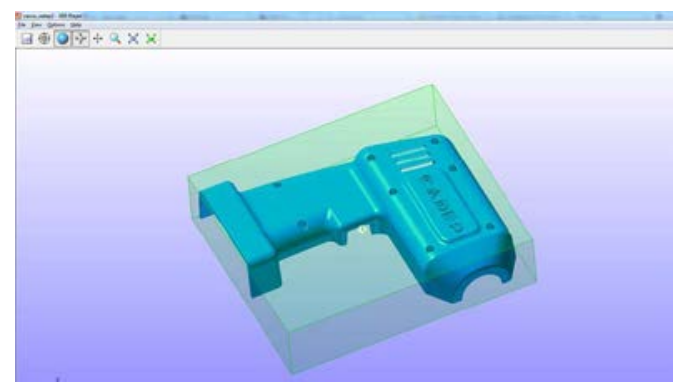

Figura 2 - SRP Player 1.23. Fonte: Elaborado pelo autor, com base na pesquisa realizada.

Para a execução deste modelo foram necessárias duas fresas, uma para desbaste e acabamento e outra para a gravação. Na primeira operação (desbaste) foi utilizada uma fresa esférica de aço da marca Hanita, com as seguintes características: diâmetro de $3 \mathrm{~mm}$, comprimento total de $75 \mathrm{~mm}$ e comprimento de corte de $25 \mathrm{~mm}$, para remover uma maior quantidade de material. Já para o acabamento (segunda operação), a peça foi usinada com a mesma fresa, mas com parâmetros diferentes, e o detalhamento foi feito com uma ferramenta de aço para gravação da marca Onsrud, com as seguintes características: diâmetro do corpo de $6 \mathrm{~mm}$, diâmetro de corte de 5 $\mathrm{mm}$, ângulo de corte de $30^{\circ}$ e largura da ponta de $0,2 \mathrm{~mm}$. (Figura 3)

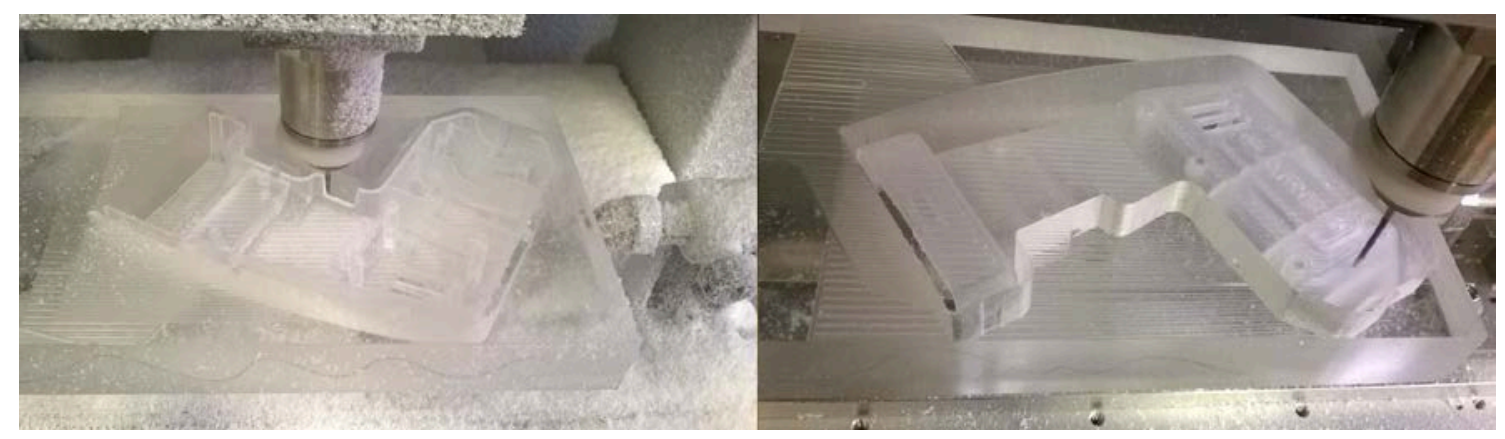

Figura 3 - Na imagem à esquerda, desbaste, e à direita, acabamento, executados pela MDX 540.

Fonte: Elaborado pelo autor, com base na pesquisa realizada.

Para a elaboração da peça na Envisiontec Ultra, houve a necessidade da criação de suportes para sustentação na plataforma e correção de pequenas falhas na malha de triângulos, feitas através do software Magics Envisiontec Ultra 1.0. Posteriormente, a peça foi posicionada na plataforma de construção do equipamento, através do software Perfactory Start Center 2.7, e finalmente enviada para o software Ultra Control, para iniciar a confecção do modelo. (Figura 4) 


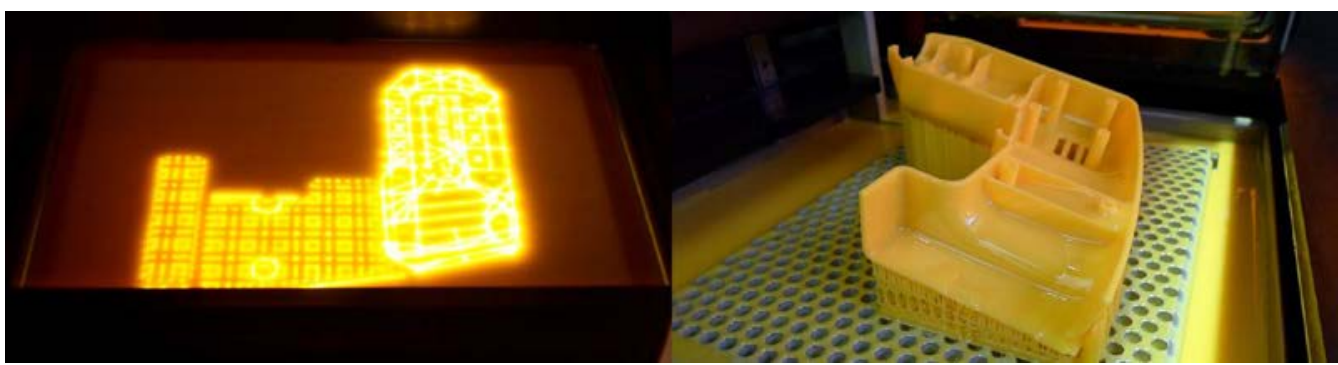

Figura 4 - Produção da peça na Envisiontec Ultra.

Fonte: Elaborado pelo autor, com base na pesquisa realizada.

Assim que as máquinas finalizaram os seus respectivos processos, a peça produzida pela MDX 540 foi destacada do bloco a partir do qual esta foi obtida, removendo-se os pontos de ligação entre a peça e o bloco (pontes) com o uso de uma pequena serra. Em seguida, foi lixada apenas nestes pontos. A outra peça, obtida na Envisiontec Ultra, necessitou da remoção do suporte e de um banho de álcool isopropílico, e depois foi lixada, a fim de remover as marcas causadas pelo contato com os suportes. (Figura 5)

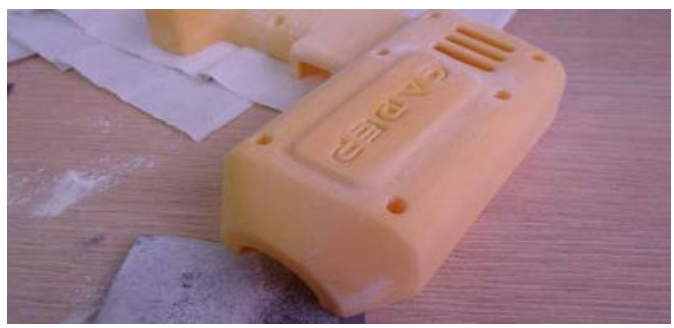

Figura 5 - Lixamento.

Fonte: Elaborado pelo autor, com base na pesquisa realizada.

\section{COMPARAÇÃO DOS PARÂMETROS}

Embora pareçam estar fiéis ao modelo CAD gerado no computador, ao serem produzidas, as peças acabam apresentando diferenças nas medidas, seja para mais ou para menos, o que pode ser um problema, dependendo do nível de precisão dimensional exigido pelo projeto. Para este estudo de caso, foi utilizado o recurso da inspeção tridimensional. Através do scanner óptico 3D GOM Atos I 2M, as peças foram digitalizadas. Em seguida, os arquivos da digitalização foram sobrepostos aos dos arquivos $C A D$, de modo a se obter as variações dimensionais.

Para a digitalização dos modelos, foram colocados adesivos dos pontos de digitalização para auxiliar na criação de uma malha poligonal a partir dos triângulos formados pela união entre os pontos. (Figura 6)

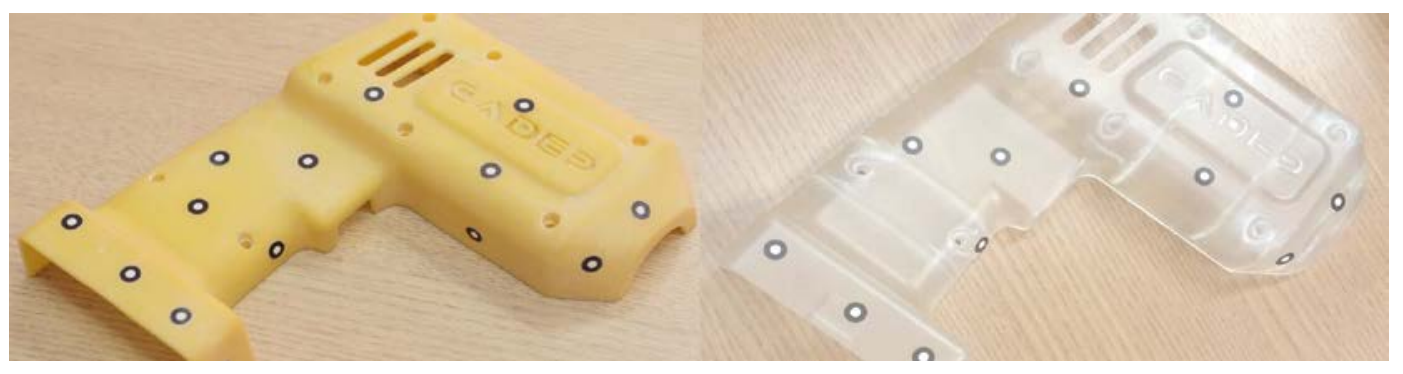

Figura 6 - Modelos com os pontos para digitalização.

Fonte: Elaborado pelo autor, com base na pesquisa realizada. 
A escala utilizada para a digitalização das peças era de $0,8 \mathrm{~mm}$, uma opção que coletou quantidades de variações de espessura e informações suficientes para as análises exigidas. Ambas as peças produzidas foram digitalizadas e os arquivos foram sobrepostos ao arquivo CAD original, utilizando o software ATOS Professional V 7.5 SR1. (Figura 7)

As figuras 8 e 9 representam a digitalização das peças produzidas nas máquinas MDX 540 e Envisiontec Ultra, respectivamente. Quanto mais áreas verdes, mais fiel a peça está em relação ao seu arquivo CAD; já as áreas em vermelho representam dimensões maiores, enquanto as áreas em azul representam dimensões menores em relação ao CAD.

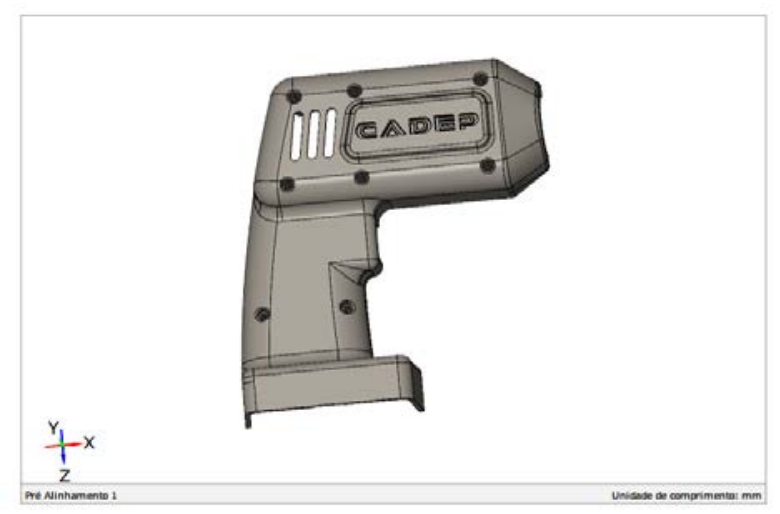

Figura 7 - Arquivo CAD utilizado para a produção das peças.

Fonte: Elaborado pelo autor, com base na pesquisa realizada.

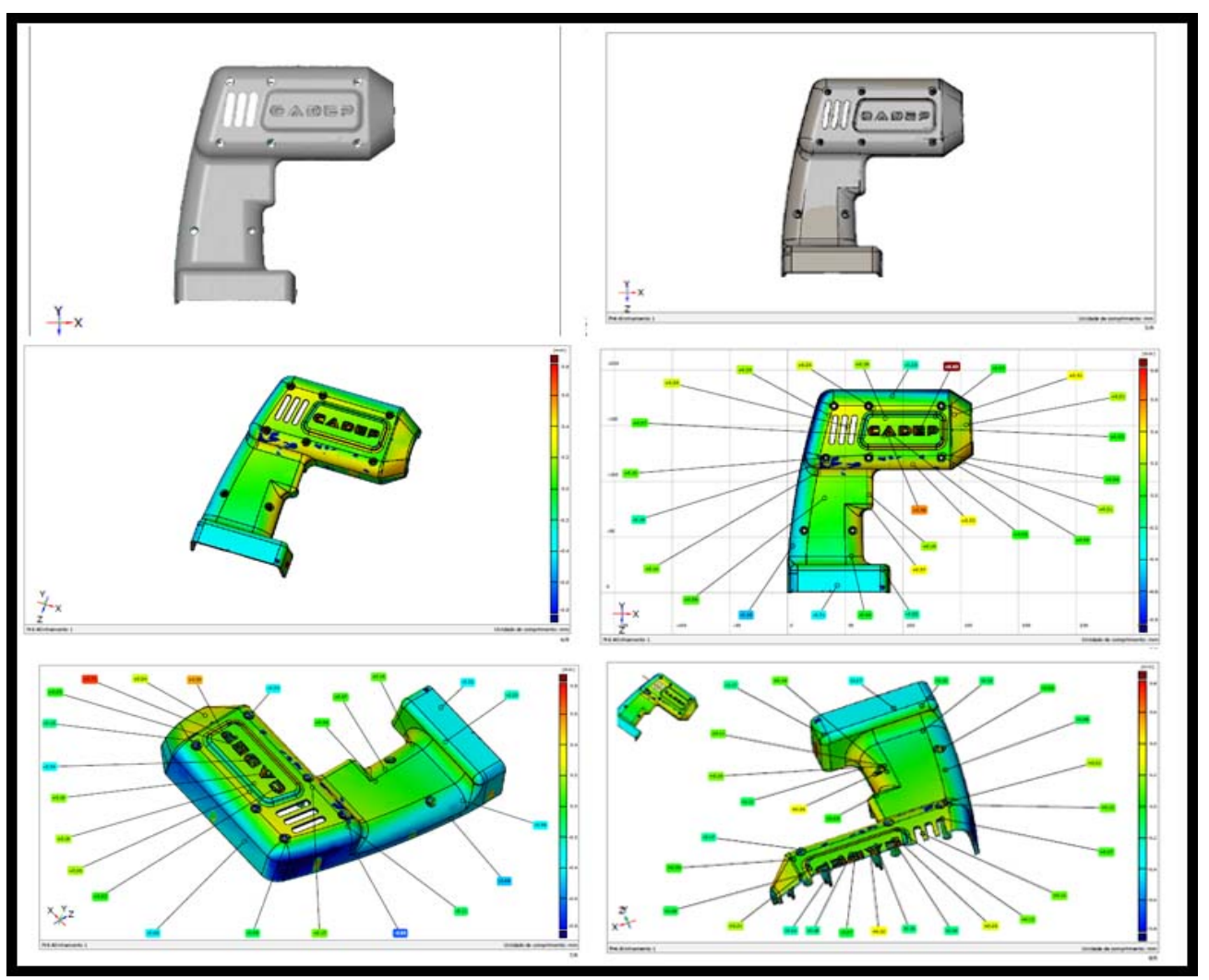

Figura 8 - Arquivo digitalizado do modelo produzido pela MDX 540 e os parâmetros obtidos. Fonte: Elaborado pelo autor, com base na pesquisa realizada. 


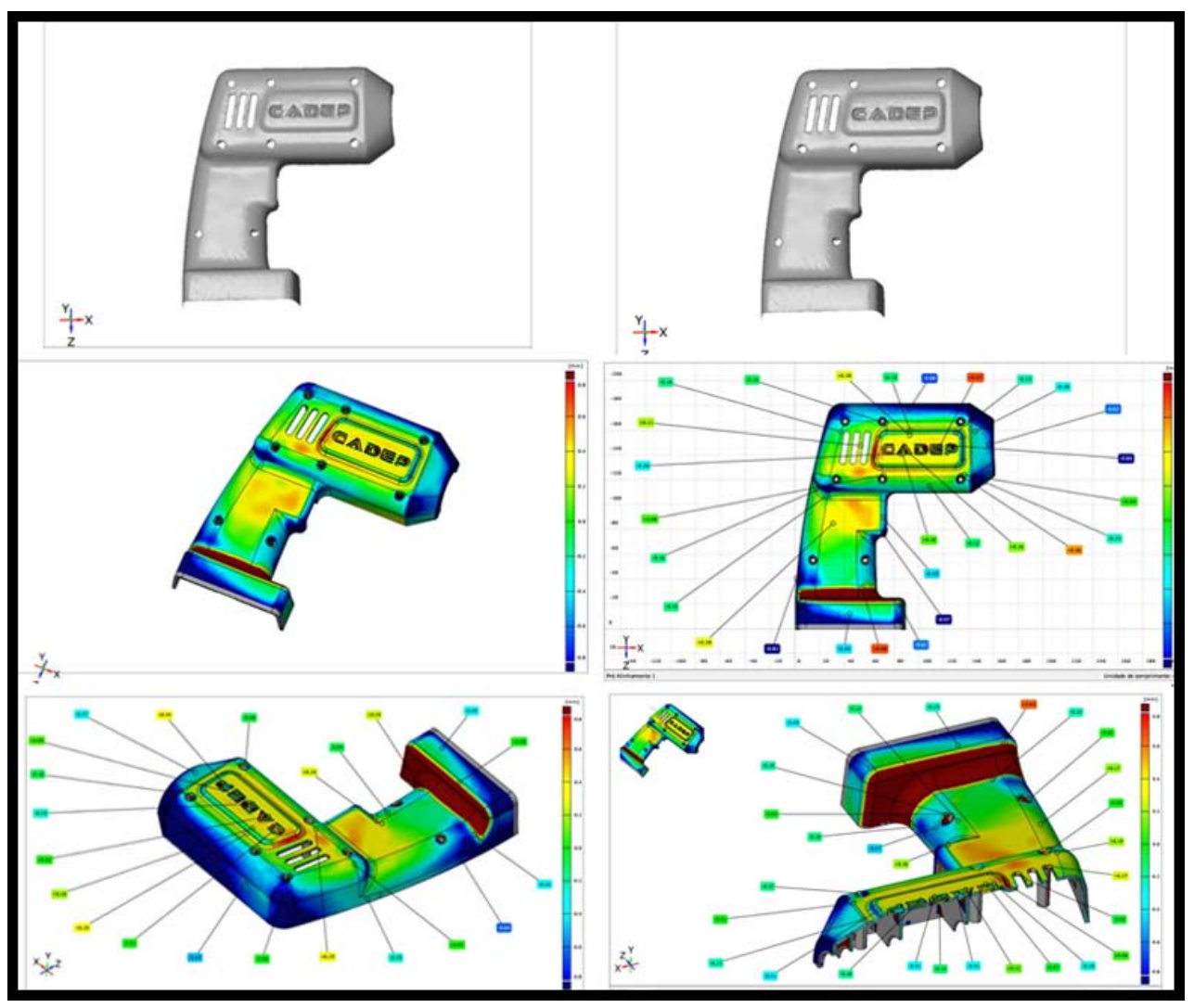

Figura 9 - Arquivo digitalizado do modelo produzido pela Envisiontec Ultra e os parâmetros obtidos. Fonte: Elaborado pelo autor, com base na pesquisa realizada.

\section{ANÁLISE DOS PARÂMETROS E RESULTADOS}

Conforme o Quadro 2, enquanto a peça feita na MDX 540 levou 32 horas e 40 minutos para ser executada, na Envisiontec Ultra ela foi confeccionada em 6 horas e 16 minutos. Porém, enquanto a peça usinada necessitou apenas ser removida do bloco de acrílico e um rápido lixamento, a peça em resina SI500 impressa em 3D exigiu, antes da remoção de suportes e lixamento, um banho em álcool isopropílico por 12 horas. Na variável "preço", a MDX 540 produziu uma peça R\$124,00 mais barata.

Quanto à fidelidade dimensional, os parâmetros apontaram que a peça produzida pela MDX 540, se mostrou mais fiel ao arquivo original, não apenas com menos variações de espessura, como também com menos deformações superficiais em relação à peça obtida pela Envisiontec Ultra.

Como o processo de Inspeção Tridimensional, comparando o arquivo da digitalização com o arquivo CAD original, foi realizado após o lixamento, ele detectou as diferenças dimensionais em função dos processos como um todo, tanto a produção da peça quanto o seu lixamento, o que pode ter causado também uma pequena alteração superficial. Ou seja, já havia certa diferença dimensional entre os arquivos sem o lixamento, e que, com ele, aumentou ainda mais.

Estes resultados comprovam que as tecnologias subtrativas, embora sejam menos consideradas do que as aditivas em Prototipagem Rápida, apresentam potencial igual ou superior, em alguns casos, às tecnologias aditivas, no PDP. 
Quadro 2 - Comparação entre a Tecnologia Aditiva e a Tecnologia Subtrativa.

\begin{tabular}{|c|c|c|}
\hline & $\begin{array}{l}\text { Tecnologia Aditiva } \\
\text { (“Envisiontec Ultra") }\end{array}$ & $\begin{array}{l}\text { Tecnologia Subtrativa } \\
\text { (“MDX 540") }\end{array}$ \\
\hline Material & $\begin{array}{l}\text { - Resina SI500 } \\
\text { - Devido ao segredo industrial, a } \\
\text { composição química do material não } \\
\text { é informada, sabendo-se apenas que } \\
\text { esta possui } 85 \% \text { das características do } \\
\text { ABS (Acrilonitrila Butadieno Estireno). } \\
\text { - Depois de produzida, a peça não } \\
\text { pode ser reciclada, inclusive o } \\
\text { suporte gerado é descartado. }\end{array}$ & $\begin{array}{l}\text { - Acrílico (PMMA - } \\
\text { Polimetilmetacrilato) } \\
\text { - O acrílico foi escolhido por ser um } \\
\text { material que ao ser usinado, } \\
\text { utilizaria os mesmos parâmetros de } \\
\text { usinagem do ABS, e que } \\
\text { proporcionaria um resultado } \\
\text { superficial semelhante à peça } \\
\text { impressa em 3D pela Envisiontec } \\
\text { Ultra. } \\
\text { - O acrílico é um material que pode } \\
\text { ser reciclado. } \\
\text { - A parte excedente do bloco } \\
\text { utilizado pode ser reaproveitada } \\
\text { para a usinagem de peças menores. }\end{array}$ \\
\hline $\begin{array}{l}\text { Tempo de } \\
\text { Produção }\end{array}$ & 6 horas e 16 minutos & 32 horas e 40 minutos \\
\hline $\begin{array}{l}\text { Pós } \\
\text { processamento } \\
\text { e acabamento }\end{array}$ & $\begin{array}{l}\text { - Os suportes da peça foram } \\
\text { removidos e ela precisou ficar imersa } \\
\text { em álcool isopropílico por } 12 \text { horas, } \\
\text { para a resina ser curada. } \\
\text { - Após a remoção dos suportes, as } \\
\text { marcas na superfície da peça, } \\
\text { causadas por eles, foram removidas } \\
\text { com lixamento. } \\
\text { - Em função do nível de } \\
\text { detalhamento do logo em baixo } \\
\text { relevo, não foi possível obter o } \\
\text { mesmo nível de acabamento } \\
\text { superficial em comparação com a } \\
\text { peça usinada. }\end{array}$ & $\begin{array}{l}\text { - A peça saiu da máquina com ótimo } \\
\text { acabamento superficial, e apenas } \\
\text { precisou ser removida do bloco de } \\
\text { acrílico. } \\
\text { - As pequenas áreas de contato das } \\
\text { pontes entre a peça e o bloco foram } \\
\text { lixadas para um melhor } \\
\text { acabamento. }\end{array}$ \\
\hline Custo & $\mathrm{R} \$ 1.314,00$ & $\mathrm{R} \$ 1.190,00$ \\
\hline
\end{tabular}

Fonte: Elaborado pelo autor, com base na pesquisa realizada.

\section{CONCLUSÃO}

O objetivo deste trabalho era apontar as vantagens e desvantagens do uso de dois processos de PR na fabricação de uma mesma peça. Para estas comparações, foram produzidos dois corpos de furadeira, cujo arquivo em 3D foi obtido através de um modelo open source. Embora as tecnologias de Prototipagem Rápida utilizadas neste artigo tenham sistemas de produção e insumos diferentes, elas conseguiram produzir a mesma peça, porém com resultados diferentes.

Se a peça possui geometria complexa, com formas intrincadas, ou precisa, por exemplo, já ser obtida com parte de seus componentes já em seus devidos lugares, dispensando montagens, recomenda-se o uso das tecnologias aditivas. Uma das principais vantagens destes tipos de tecnologias, é que, depois de executadas, dependendo da aplicação, as peças já saem da máquina praticamente prontas para o 
uso, restando apenas finalizar alguns detalhes, como a ação de curar a peça, limpar os resíduos de insumo, remover possíveis suportes (estruturas de sustentação na construção das peças) e lixar.

Entretanto, se a peça a ser produzida não possuir formas complexas ou inacessíveis às ferramentas de usinagem; se for necessário o uso do mesmo material a ser utilizado durante o processo de produção em série da referida peça, ou equivalente - a Envisiontec Ultra opera com pouquíssimas opções de resina, e boa parte das vezes não adequada à necessidade e aplicações em larga escala -; se for necessária a obtenção de uma peça que também exija um elevado nível de precisão dimensional, e ao mesmo tempo um elevado nível de acabamento superficial, e ainda a um custo mais baixo, recomenda-se o uso das tecnologias subtrativas.

Segundo Junior (2008), "Não é possível estabelecer a melhor tecnologia, mas sim estabelecer que para se construir um protótipo eficiente é necessário saber o que se quer dele no desenvolvimento do produto que este protótipo representa".

Portanto, conclui-se que a escolha da melhor tecnologia dependerá da finalidade do protótipo e o que se pretende atingir com ele. Se será apenas um objeto para estudos, se será utilizado como molde, ferramenta ou como produto final. Também deve se levar em conta a quantidade de verba disponível para a execução da peça, níveis de detalhamento e precisão exigidos, tamanho, complexidade geométrica e tempo disponível para produção.

Um dos objetivos de qualquer profissional envolvido com PDP é a melhoria desse Processo, e estas novas tecnologias são capazes de auxiliá-lo neste sentido. Por isso, é muito importante que se escolha uma tecnologia adequada para a produção de modelos e protótipos, a fim de se obter peças que correspondam às expectativas e que cumpram seu propósito no PDP.

\section{AGRADECIMENTOS}

Ao CADEP/UNESP (Centro Avançado de Desenvolvimento de Produtos) e seus bolsistas, e à CAPES (Coordenação de Aperfeiçoamento de Pessoal de Nível Superior) pelo suporte nesta pesquisa.

\section{REFERÊNCIAS}

ALENCAR, F.; RODRIGUES, O.V.; BARATA T. Q. F.; BARTOLO, P. J. Comparative analysis of dimensional deviations between CAD model and physical models obtained by additive manufacturing technologies by means of optical scanning with structural light projection. In: $5^{\text {th }}$ International PMI Conference Proceedings. Ghent: University College Ghent, 2012. V. 1, P. $82-85$.

JUNIOR, Aguilar Selhorst. Análise comparativa entre os processos de prototipagem rápida na concepção de novos produtos: um estudo de caso para determinação do processo mais indicado. Diss. Pontifícia Universidade Católica do Paraná, 2008.

JUNIOR, Osiris Canciglieri; JUNIOR, Aguilar Selhorst; NETO, Alfredo larozinski. Processos de Prototipagem Rápida por deposição ou remoção de material na concepção de novos produtos-uma abordagem comparativa. XXVII Encontro Nacional de Engenharia de Produção. Foz do Iguaçu, 2007. Disponível na internet por http em: < http://www.abepro.org.br/biblioteca/enegep2007_tr610459_0570.pdf>. Acesso em: 18 fev. 2016. 
RODRIGUES, O.V.; Cascajosa, J.M.D. Veterinary Aditive Manufacturing: development of a prosthesis of a Toucan's bill. In: Rapid, 2015. Long Beach CA: Long Beach Convention Center, 2015.

RODRIGUES, O. V.; ALENCAR, F.; BARATA T. Q. F. Combining Rapid Prototyping with more conventional production processes. In: $5^{\text {th }}$ International PMI Conference Proceedings. Ghent: University College Ghent, 2012. V. 1, P. 147- 150.

VASCONCELOS, P.; LINO, F. J. \& NETO, R. J. O fabrico rápido de ferramentas ao serviço da engenharia concorrente. Portugal: TECNOMETAL, 2001. Disponível na internet por http em: <http://paginas.fe.up.pt/ falves/arttecnometal.pdf>. Acesso em: 19 fev. 2016.

VOLPATO, Neri. Prototipagem Rápida: tecnologias e aplicações. São Paulo: Editora Blücher, 2007. 